This article was downloaded by: [Delanaye, Pierre]

On: 30 March 2009

Access details: Access Details: [subscription number 909981583]

Publisher Informa Healthcare

Informa Ltd Registered in England and Wales Registered Number: 1072954 Registered office: Mortimer House, 37-41 Mortimer Street, London W1T 3JH, UK

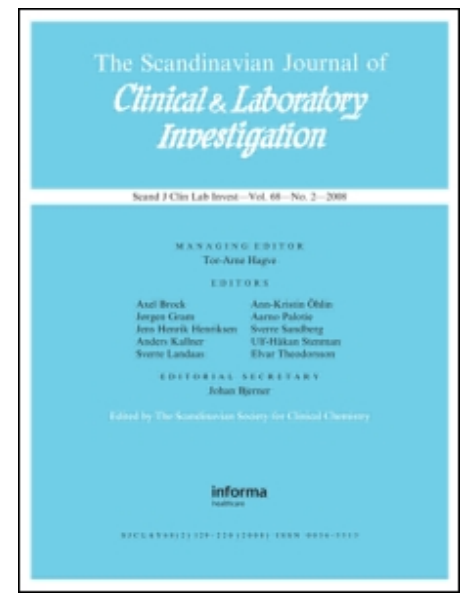

Scandinavian Journal of Clinical and Laboratory Investigation

Publication details, including instructions for authors and subscription information: http://www.informaworld.com/smpp/title content=t713625785

\title{
Discrepancies between creatinine-based and cystatin C-based equations in estimating prevalence of stage 3 chronic kidney disease in an elderly population
}

Pierre Delanaye a; Etienne Cavalier ${ }^{\mathrm{b}}$; Annie Saint-Remy a; Laurence Lutteri ${ }^{\mathrm{b}}$; Jean-Marie Krzesinski a a Department of Nephrology, ${ }^{b}$ Department of Clinical Chemistry, University of Liège, Liège, Belgium

First Published:May2009

To cite this Article Delanaye, Pierre, Cavalier, Etienne, Saint-Remy, Annie, Lutteri, Laurence and Krzesinski, JeanMarie(2009)'Discrepancies between creatinine-based and cystatin C-based equations in estimating prevalence of stage 3 chronic kidney disease in an elderly population',Scandinavian Journal of Clinical and Laboratory Investigation,69:3,344 — 349 To link to this Article: DOI: $10.1080 / 00365510802609856$

URL: http://dx.doi.org/10.1080/00365510802609856

\section{PLEASE SCROLL DOWN FOR ARTICLE}

\footnotetext{
Full terms and conditions of use: http://www.informaworld.com/terms-and-conditions-of-access.pdf

This article may be used for research, teaching and private study purposes. Any substantial or systematic reproduction, re-distribution, re-selling, loan or sub-licensing, systematic supply or distribution in any form to anyone is expressly forbidden.

The publisher does not give any warranty express or implied or make any representation that the contents will be complete or accurate or up to date. The accuracy of any instructions, formulae and drug doses should be independently verified with primary sources. The publisher shall not be liable for any loss, actions, claims, proceedings, demand or costs or damages whatsoever or howsoever caused arising directly or indirectly in connection with or arising out of the use of this material.
} 


\title{
ORIGINAL ARTICLE
}

\section{Discrepancies between creatinine-based and cystatin C-based equations in estimating prevalence of stage 3 chronic kidney disease in an elderly population}

\author{
Pierre Delanaye ${ }^{1}$, Etienne Cavalier ${ }^{2}$, Annie Saint-Remy ${ }^{1}$, Laurence Lutteri ${ }^{2}$ and Jean-Marie Krzesinski ${ }^{1}$ \\ ${ }^{1}$ Department of Nephrology and ${ }^{2}$ Department of Clinical Chemistry, University of Liège, CHU Sart Tilman, Liège, Belgium
}

\begin{abstract}
Background. The prevalence of stage 3 chronic kidney disease (CKD) is increasing, calculated using the modification of diet in renal disease (MDRD) study equation for estimating glomerular filtration rate (GFR). Cystatin C-based equations are also being used to estimate GFR. Using creatinine-based and cystatin C-based equations, the aim of our study was to measure the difference in prevalence of stage 3 CKD in a population. Methods. CKD screening is organized in the Province of Liège, Belgium. On a voluntary basis, people aged between 45 and 75 years are invited for screening. GFR is estimated using the MDRD study equation and by the three recent cystatin C-based equations proposed by Levey's group. The Levey 1 equation is based on cystatin $\mathrm{C}$ only and the Levey 2 equation on cystatin $\mathrm{C}$ corrected for age and sex. The Levey 3 equation combines cystatin C, creatinine, age and sex. Results. The population screened comprised 754 people. Cystatin C is highly correlated with creatinine $(r=0.6196, p<0.0001)$. Prevalence of stage 3 CKD when GFR is estimated by the MDRD equation study is $17.2 \%$, which is significantly and much higher than the prevalence obtained when cystatin Cbased equations are used. Indeed, prevalence is $2 \%, 3.3 \%$ and $5.8 \%$ with the Levey 1,2 and 3 equations, respectively. Conclusions. The prevalence of stage $3 \mathrm{CKD}$ varies strongly following the method used for estimating GFR, creatinine-based or cystatin C-based equations. Such discrepancies must be confirmed and explained in additional studies using GFR measured with a reference method.
\end{abstract}

Keywords: Chronic kidney disease; creatinine; cystatin C; glomerular filtration rate

\section{Introduction}

The prevalence of end-stage renal failure is increasing in Western countries [1] and, in this context, prevention of chronic kidney disease (CKD) is important [2]. The first step for efficient prevention is early diagnosis, but serum creatinine is of limited value for such a task, as it is known that creatinine will rise above normal values only when $50 \%$ of glomerular filtration rate (GFR) has already been lost [3,4]. Limitations of serum creatinine are numerous, but its lack of sensitivity is due especially to its relationship with muscular mass. Creatinine therefore lacks sensitivity in populations with lower muscular mass, notably the older population $[4,5]$. Several authors have proposed a creatinine-based equation to improve GFR estimation. Today, the modification of diet in renal disease (MDRD) study equation is the one most used for estimating GFR and has succeeded the older Cockcroft equation [6]. Recent epidemiological data have shown that nearly $10 \%$ of the population in the USA have stage 3 CKD or worse, defined as estimated GFR lower than $60 \mathrm{~mL} / \mathrm{min} / 1.73 \mathrm{~m}^{2}$. These results were obtained with the MDRD study equation [1]. However, we and others have emphasized that the MDRD equation is neither accurate nor precise in estimating GFR in healthy populations and, more obviously, when it is applied to normal creatinine values [7-9]. There are several good reasons for believing that the MDRD study equation underestimates GFR (and thus overestimates CKD prevalence) in populations with normal or near-normal creatinine values $[7,8]$.

Plasma cystatin $\mathrm{C}$ is a relatively new marker of GFR. Indeed, although strong physiological studies are few in number, cystatin $\mathrm{C}$ is constantly produced by all nucleated cells of the body, freely filtrated through the glomeruli and neither reabsorbed nor secreted by the tubules. It is fully catabolized in the proximal tubules [10-12]. Cystatin $\mathrm{C}$ has been shown of interest in the early detection of decreased kidney function. Moreover, several equations based on cystatin C level have been built to estimate GFR. However, most have been elaborated from a limited sample and have been poorly validated $[10,12]$. Recently, Levey's group, which is at the origin of the MDRD study equation, has elaborated three

Correspondence: Pierre Delanaye, Service de Dialyse, CHU Sart Tilman, 4000 Liège, Belgium. Tel: +32 43667111. Fax: +32 43667205. Email: pierre_delanaye@ yahoo.fr 
cystatin C-based equations with different variables from a large sample of CKD patients $(n=2980)$ : Levey 1 with cystatin $\mathrm{C}$ as the only variable, Levey 2 including cystatin $\mathrm{C}$, age, sex and race as variable and Levey 3 including these same variables and the serum creatinine [13]. It has been interesting to evaluate the prevalence of CKD (defined as estimated GFR under $60 \mathrm{~mL} / \mathrm{min} / 1.73 \mathrm{~m}^{2}$ ) with the MDRD study equation, on the one hand, and with these three new cystatin $\mathrm{C}$-based equations, on the other.

\section{Method}

This retrospective study was driven in the context of the CKD screening programme organized by the Province of Liège's Health deputation. The Province of Liège, one of the 10 provinces in Belgium, covers an area of $3862 \mathrm{~km}^{2}$ and its population from 2005 data has been calculated at 1,037,161 inhabitants. CKD screening is organized by participants visiting a mobile medical unit travelling through the 84 communes of the Province. On a voluntary basis, people aged between 45 and 75 years are invited for screening. Blood samples and anthropometrical data are collected and a short interview is carried out. The blood samples are sent frozen to the Clinical Chemistry Laboratory of the University of Liège within the following $24 \mathrm{~h}$. Between September and December 2006, all the samples were frozen at $-20^{\circ} \mathrm{C}$ and in January and February 2008 they were thawed. Serum creatinine was measured by the IDMS traceable enzymatic method from Roche (Crea plus; Roche Diagnostics, Mannheim, Germany) on a Hitachi 917. For creatinine determination, our laboratory has been enrolled in different external quality assessments, such as the Belgian IPH (Institute of Public Health) and German DGKL (Deutsche Gesellschaft für Klinische Chemie und Laboratoriumsmedizin). This assay is also currently accredited against the ISO 15189 Standard. Cystatin $\mathrm{C}$ was measured by particle-enhanced nephelometric immunoassay (PENIA) on the BNII nephelometer (Siemens Healthcare Diagnostics, ex-Dade-Behring, Marburg, Germany). This PENIA assay is the same as the one that Levey et al. used in their study. The equations are given in Table I. As our creatinine is IDMS traceable, we used the new "175" MDRD study equation [6].

A random spot urine was obtained and proteinuria was researched by dipstick analysis (Combur ${ }^{3}$; Roche Diagnostics, Mannheim, Germany). Hypertension and diabetes were self-reported by the participants.

As the distribution of estimated GFRs by creatinine-based equations is not normal, the
Table I. Creatinine-based ( $\mathrm{S} \mathrm{Cr} ; \mathrm{mg} / \mathrm{dL}$ ) and cystatin $\mathrm{C}$ based $(\mathrm{CC} ; \mathrm{mg} / \mathrm{L})$ equations for estimating glomerular filtration rate (GFR).

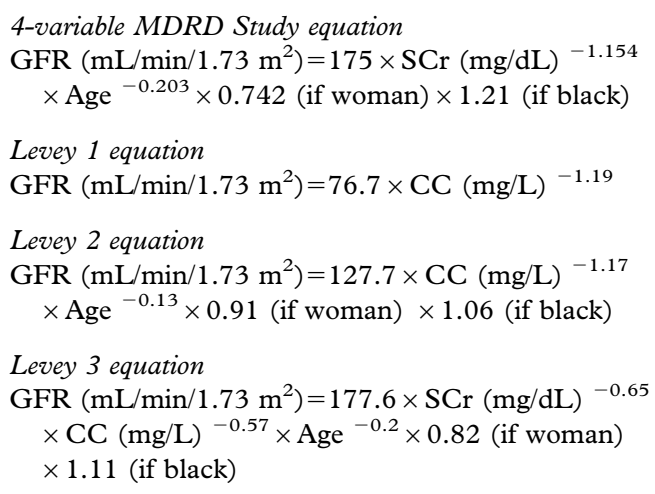

different results of estimated GFR were compared using the Wilcoxon test. We calculated and compared the percentage of patients with stage 3 CKD or worse (stage 3 CKD being defined as an estimated GFR under $60 \mathrm{~mL} / \mathrm{min} / 1.73 \mathrm{~m}^{2}$ ) obtained with the four equations, and the coefficients of correlation between the different equations were calculated. Agreement between equations to discriminate GFR above and below $60 \mathrm{~mL} / \mathrm{min} / 1.73 \mathrm{~m}^{2}$ was evaluated by Kappa statistics. We also compared the results of GFR estimated by the MDRD study equation, on the one hand, and the results of GFR estimated by the cystatin C-based equations, on the other, by Bland and Altman analysis [14]. In these analyses, we arbitrarily chose the creatinine-based equation results as the referent. As cystatin $\mathrm{C}$ is not (or very little) dependent on muscular mass, we specifically studied a subgroup of patients based on body mass index ( $>$ or $<30 \mathrm{~kg} / \mathrm{m}^{2}$ ). Bias between equations was defined as the mean of the differences. The SD around the mean reflects the dispersion and precision of the equations. $P<0.05$ was considered as significant. All analyses were performed using $\mathrm{MedCalc}^{\circledR}$ (MedCalc Software; Mariakerke, Belgium).

\section{Results}

During the study period, 754 people were screened (48.7\% male and $51.3 \%$ female). The anthropometric, clinical and biological characteristics of the global population are given in Table II. There is no difference between men and women in relation to anthropometrical and clinical data, nor are mean creatinine and cystatin $\mathrm{C}$ different between the sexes. As the Levey 1 equation does not include a sex factor correction, there is logically no difference between the mean values obtained with this equation in men and women. However, mean estimated GFR is 
Table II. Anthropometric and biological description of the population $(n=754)$. Data are expressed as mean \pm SD.

\begin{tabular}{lcc}
\hline$N=754$ & Mean & SD \\
\hline Age & 61.3 & 8.6 \\
Weight $(\mathrm{kg})$ & 74.7 & 14.7 \\
Height $(\mathrm{cm})$ & 167 & 9 \\
BMI $\left(\mathrm{kg} / \mathrm{m}^{2}\right)$ & 26.6 & 4.3 \\
Current smokers (\%) & 23.6 & \\
Diabetes (\%) & 12.8 & \\
Hypertension (\%) & 31.7 & \\
Proteinuria (\%) & 18 & 0.2 \\
Creatinine (mg/dL) & 0.86 & 0.16 \\
Cystatin C (mg/L) & 0.76 & 26 \\
MDRD study (mL/min/ & 83 & \\
$\left.\quad 1.73 \mathrm{~m}^{2}\right)$ & & 23 \\
Levey 1 & 109 & 23 \\
Levey 2 & 101 & 24 \\
Levey 3 & 95 & \\
\hline
\end{tabular}

significantly different between the sexes (and lower in women) when the MDRD study equations are analysed $\left(97 \pm 24\right.$ versus $\left.72 \pm 28 \mathrm{~mL} / \mathrm{min} / 1.73 \mathrm{~m}^{2}\right)$, the Levey $2(106 \pm 24$ versus $96 \pm 20 \mathrm{~mL} / \mathrm{min} /$ $\left.1.73 \mathrm{~m}^{2}\right)$ and the Levey $3(105 \pm 24$ versus $86 \pm 20 \mathrm{~mL} / \mathrm{min} / 1.73 \mathrm{~m}^{2}$ ).

Cystatin $\mathrm{C}$ is highly correlated with creatinine $(r=0.6216, p<0.0001)$. Plasma cystatin $\mathrm{C}$ and serum creatinine are correlated with age in our population $(p<0.0001)$, correlation being significantly higher for cystatin $\mathrm{C}$ than for creatinine $(r=0.4096$ and $r=0.1960$, respectively).

With the Wilcoxon test, all the estimated GFRs are different from each other $(p<0.0001)$. The prevalence of stage $3 \mathrm{CKD}$ when GFR is estimated by the MDRD equation study is $17.2 \%$. This prevalence is significantly much higher than that obtained when cystatin C-based equations are used. Indeed, the prevalences of stage 3 CKD are $2 \%$ and $3.3 \%$ with the Levey 1 and 2 equations, respectively (no difference between these two equations). The prevalence of stage $3 \mathrm{CKD}$ with the combined (creatinine and cystatin C) Levey 3 equation is significantly $(5.8 \%)$ lower than with the MDRD study equation, but significantly higher than with the Levey 1 and 2 equations. Kappa statistics show poor agreement between creatinine-based and cystatin Cbased equations for discriminating GFR under and over $60 \mathrm{~mL} / \mathrm{min} / 1.73 \mathrm{~m}^{2}(\kappa<0.2)$.

All equation results are highly correlated $(p<0.0001)$. The coefficients of correlation between the equations are given in Table III. All the correlations are statistically different, with the best correlation logically seen between the Levey 1 and 2 equation results and the weakest between the MDRD study and the Levey 1 study equation results.
Table III. Correlation between creatinine-based and cystatin C-based equations.

\begin{tabular}{lccc}
\hline & MDRD study & Levey 1 & Levey 2 \\
\hline MDRD Study & & & \\
Levey 1 & 0.51 & & \\
Levey 2 & 0.61 & 0.97 & \\
Levey 3 & 0.93 & 0.78 & 0.85 \\
\hline
\end{tabular}

The Bland and Altman analysis results are summarized in Figure 1. The mean difference between the MDRD study equation and the Levey 1 equation is $+25.3 \pm 24.2 \mathrm{~mL} / \mathrm{min} / 1.73 \mathrm{~m}^{2}$. The differences with the Levey 2 and 3 equations are $+17.4 \pm 21.5$ and $+11.9 \pm 9.5 \mathrm{~mL} / \mathrm{min} / 1.73 \mathrm{~m}^{2}$, respectively. The difference between the Levey 3 equations and the MDRD study equation is lower than the difference between the MDRD study equation and the other two Levey equations.

In the subgroup analysis based on the BMI, we show that the prevalence of CKD stage 3 is not different in the obese population whatever equation is used. In this specific subgroup $(n=148)$, the mean eGFR by the MDRD study equation is not different from the global population $(85 \pm 26$ versus $83 \pm 26 \mathrm{~mL} / \mathrm{min} / 1.73 \mathrm{~m}^{2}$, respectively). This is also the case for the Levey 3 equation $(93 \pm 24$ versus $95 \pm 24 \mathrm{~mL} / \mathrm{min} / 1.73 \mathrm{~m}^{2}$, respectively). However, for the Levey 1 and 2 equations, the results of eGFR are significantly lower in the obese population than in the global population (Levey 1: $101 \pm 22$ versus $109 \pm 23 \mathrm{~mL} / \mathrm{min} / 1.73 \mathrm{~m}^{2}$, respectively, Levey 2: $95 \pm 22$ versus $101 \pm 23 \mathrm{~mL} / \mathrm{min} / 1.73 \mathrm{~m}^{2}$, respectively).

\section{Discussion}

Epidemiologic studies in different Western countries have recently shown that prevalence of CKD, defined as GFR under $60 \mathrm{~mL} / \mathrm{min} / 1.73 \mathrm{~m}^{2}$, is about $10 \%$ in the global population $[1,15]$. These data have been obtained with the MDRD study equation using a well-calibrated serum creatinine $[16,17]$. However, the use of this equation is not free from criticism. We have recently demonstrated that this equation tends to underestimate GFR strongly in healthy populations and, more generally, in patients with normal or near normal creatinine values $[7,8]$. Cystatin $\mathrm{C}$ is thought to be a better marker of kidney function, especially because its concentration is less influenced by muscular mass than serum creatinine $[12,18]$. Several cystatin C-based equations have been proposed for estimating GFR and the recent cystatin Cbased equations proposed by Levey et al. will certainly be the most successful in the future, because these three equations have been built from studies 
A

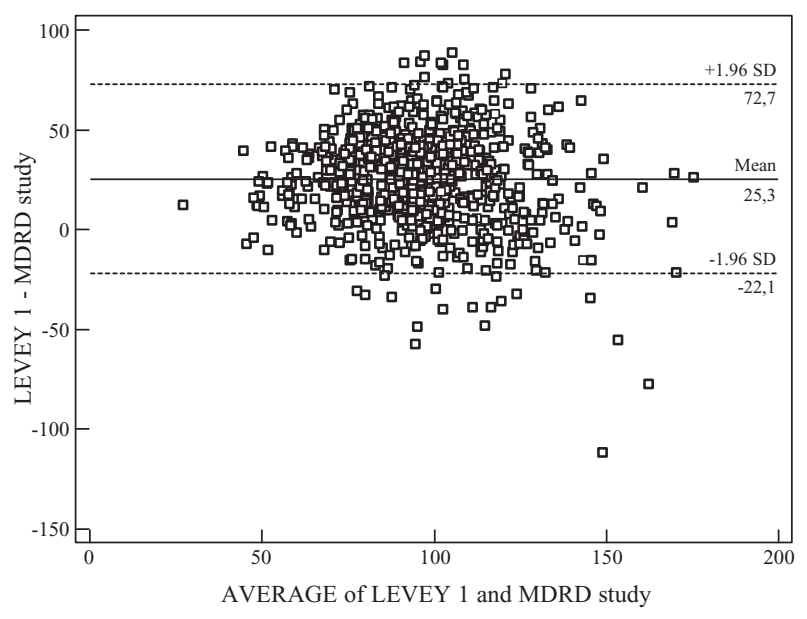

B

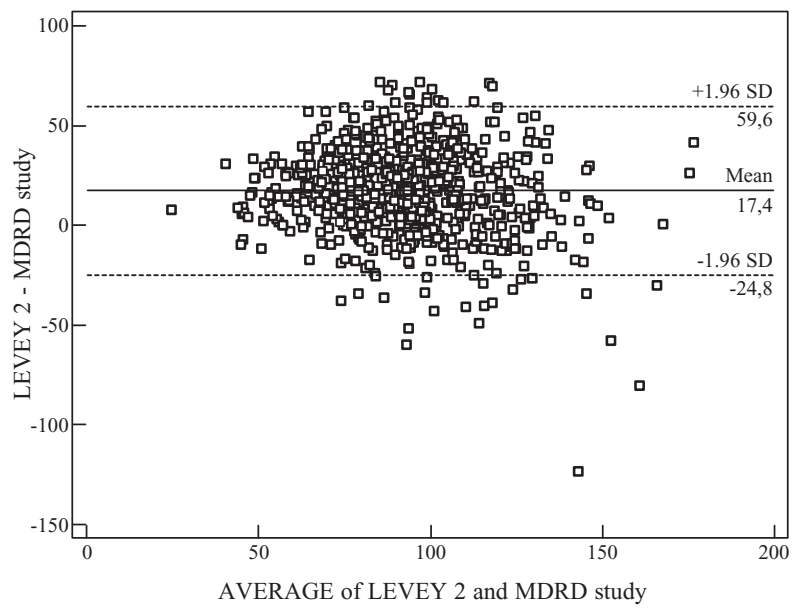

$\mathrm{C}$

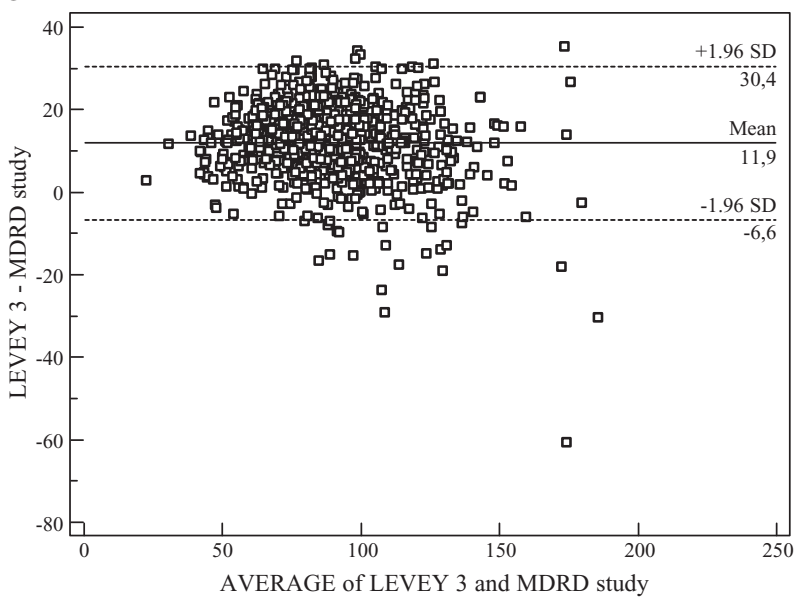

Figure 1. Bland and Altman analysis between the MDRD study equation and the three new Levey equations (A: Levey 1, B: Levey 2, C: Levey 3). The continuous line represents the mean difference between measured and estimated GFR, whereas the dashed lines represent the limits of agreement (mean difference $\pm 2 \mathrm{SD}$ ). All values are expressed in $\mathrm{mL} / \mathrm{min} / 1.73 \mathrm{~m}^{2}$. with a large sample of patients [13]. In our population of volunteers, the prevalence of CKD is strongly discordant using creatinine-based or cystatin C-based equations. Indeed, if the prevalence of stage $3 \mathrm{CKD}$ is as high as $17 \%$ using the MDRD study equations, the prevalence will decrease to $2 \%, 3.3 \%$ and $5.8 \%$ for the equations based on cystatin $\mathrm{C}$ concentrations only, on cystatin $\mathrm{C}$, sex and age, and on cystatin $\mathrm{C}$ and creatinine concentrations sex and age, respectively. It seems logical to have a less important (although significant) difference between the results obtained with the MDRD and the Levey 3 equation than between the MDRD and the Levey 1 and 2 equations, as serum creatinine is part of the Levey 3 equation. From our point of view, and as other authors have also shown, the MDRD study equation underestimates GFR in healthy populations because this equation has been built from a CKD population (and the relationship between creatinine and GFR is not the same in healthy or in CKD patients) $[9,19]$ and because the new factor 175 in the IDMS traceable equation has been obtained erroneously [7]. Moreover, the mean age of our study population is relatively high ( $61 \pm 9$ years) and the accuracy and precision of the MDRD study equation are probably still less in aged populations with low creatinine values [20]. Regarding the cystatin C-based equations, it may also be of interest to compare our population with the population where the three equations have been built. The population studied by Levey is a CKD population (mean GFR: $48 \pm 25 \mathrm{~mL} / \mathrm{min} / 1.73 \mathrm{~m}^{2}$ ) [13]. However, contrary to creatinine, there is no reason to believe that the relationship between cystatin C and GFR is different in CKD and non-CKD populations. The Levey population is an American one and our subjects are European. The American Levey equation has still not been validated in a European population but, using another European built cystatin $\mathrm{C}$ equation [21] $\left(\mathrm{eGFR}=77.24 \times \mathrm{CC}(\mathrm{mg} / \mathrm{L})^{-1.2623}\right)$, we found exactly the same prevalence of stage $3 \mathrm{CKD}$ as with the Levey 1 equation (i.e. $1.99 \%$ ). Our population is also older than the Levey population ( $61 \pm 9$ years old versus $52 \pm 13$ years), but the influence of age seems of limited importance as there is no difference in the prevalence of our population using either the Levey 1 equation (using only cystatin C) or the Levey 2 equation (using cystatin $\mathrm{C}$ and age). Another point is that our population has a lower BMI than in the Levey population $\left(27 \pm 4\right.$ versus $\left.29 \pm 6 \mathrm{~kg} / \mathrm{m}^{2}\right)$. For some authors, cystatin $\mathrm{C}$ is not strictly independent of weight and muscular mass [18,22]. As cystatin $\mathrm{C}$ is higher in heavier patients, and as our patients are lighter than patients in the Levey study, the Levey equations should slightly underestimate GFR in our 
population. The prevalence of stage $3 \mathrm{CKD}$ with the cystatin C-based equations could theoretically still be overestimated in our population.

Obesity and age are both factors of risk for CKD [23]. However, no difference is found in stage 3 CKD prevalence when the creatinine-based equations (MDRD and Levey 3) are used between the global and the obese populations. On the other hand, the eGFR in the obese population is significantly lower with the cystatin C-based equations than in the global and non-obese population. This could be an indirect argument in favour of cystatin C-based equations, but the absence of true GFR measurement does not permit conclusions to be drawn.

The main limitation of our study is linked to the fact that we have not measured GFR with a reference method. So, even if we have indirect arguments affirming that MDRD study equations overestimate CKD prevalence in global populations, such an assertion can only be made if a reference method GFR is used. The new cystatin Cbased equations must also be validated against measured GFR. In the same way, we are unable to confirm that the combined equation (Levey 3 ) is better for estimating GFR than the other two cystatin C-based equations. Our data only underline potential strong discrepancies between results in epidemiological studies when cystatin C-based or creatinine-based equations are used. Second, our stage 3 CKD prevalence data are of interest only because they illustrate these discrepancies. As our population is clearly not representative of the Belgian population (because only volunteers are included), our stage 3 CKD prevalence results cannot be considered epidemiologically. Thirdly, we have no data on ethnicity. As the ethnicity factor varies following the equations, this could be a source of bias. However, in Belgium, Caucasians are, by far, the dominant ethnic group. Moreover, there is little doubt that the differences observed in our study are not due to the ethnic factor (1.21 for the MDRD study equation, 1.06 and 1.11 for the Levey 2 and Levey 3 equations, respectively). Fourthly, plasma cystatin C concentration seems dependent on thyroid status and is influenced by steroid therapy independently of any GFR changes. These potential interferences have not been considered in our study [24,25]. Nevertheless, great discrepancies between creatinine and cystatin Cbased results are certainly not fully explained by these potential interferences. Lastly, we have defined CKD as GFR $<60 \mathrm{~mL} / \mathrm{min} / 1.73 \mathrm{~m}^{2}$. The definition of CKD is subject to debate, however, notably in the elderly population [26]. Whatever, our data do not bring an end to this debate.
In conclusion, the present study illustrates large discrepancies in the prevalence of stage 3 CKD in a population according to the method used for estimating GFR (creatinine-based or cystatin Cbased). We disfavour the MDRD study equations in epidemiological studies. More research is urgently needed to confirm and explain these discrepancies. Population studies using GFR measurements with a reference method are required.

\section{Acknowledgements}

We thank Rosalie Bonmariage for her help during editing of this manuscript and also G. Pire, Deputy of the Health Department of the Province of Liège, and Dr Maasen. We also thank the Guy Mathot Foundation.

Declaration of interest: The authors report no conflicts of interest. They alone are responsible for the content and writing of the paper.

\section{References}

[1] Coresh J, Selvin E, Stevens LA, Manzi J, Kusek JW, Eggers P, Van Lente F, Levey AS. Prevalence of chronic kidney disease in the United States. J Am Med Assoc 2007;298:2038-47.

[2] Hallan SI, Vikse BE. Relationship between chronic kidney disease prevalence and end-stage renal disease risk. Curr Opin Nephrol Hypertens 2008;17:286-91.

[3] Couchoud C, Pozet N, Labeeuw M, Pouteil-Noble C. Screening early renal failure: cut-off values for serum creatinine as an indicator of renal impairment. Kidney Int 1999;55:1878-84.

[4] Perrone RD, Madias NE, Levey AS. Serum creatinine as an index of renal function: new insights into old concepts. Clin Chem 1992;38:1933-53.

[5] Lamb EJ, O'Riordan SE, Delaney MP. Kidney function in older people: pathology, assessment and management. Clin Chim Acta 2003;334:25-40.

[6] Levey AS, Coresh J, Greene T, Stevens LA, Zhang YL, Hendriksen S, Kusek JW, Van Lente F. Using standardized serum creatinine values in the modification of diet in renal disease study equation for estimating glomerular filtration rate. Ann Intern Med 2006;145:247-54.

[7] Delanaye P, Cavalier E, Maillard N, Krzesinski JM, Mariat C. Creatinine calibration in NHANES: is a revised MDRD study formula needed? Am J Kidney Dis 2008;51:709-10.

[8] Delanaye P, Cavalier E, Krzesinski JM. Determining prevalence of chronic kidney disease using estimated glomerular filtration rate. J Am Med Assoc 2008;299:631.

[9] Froissart M, Rossert J, Jacquot C, Paillard M, Houillier P. Predictive performance of the modification of diet in renal disease and Cockcroft-Gault equations for estimating renal function. J Am Soc Nephrol 2005;16:763-73.

[10] Newman DJ. Cystatin C. Ann Clin Biochem 2002;39:89-104.

[11] Grubb AO. Cystatin C-properties and use as diagnostic marker. Adv Clin Chem 2000;35:63-99.

[12] Seronie-Vivien S, Delanaye P, Pieroni L, Mariat C, Froissart M, Cristol JP. Cystatin C: point d'étape et perspectives. Ann Biol Clin (Paris) 2008;66:301-23.

[13] Stevens LA, Coresh J, Schmid CH, Feldman HI, Froissart M, Kusek J, Rossert J, Van Lente F, Bruce RD III, Zhang YL, 
Greene T, Levey AS. Estimating GFR using serum cystatin C alone and in combination with serum creatinine: a pooled analysis of 3,418 individuals with CKD. Am J Kidney Dis 2008;51:395-406.

[14] Bland JM, Altman DG. Statistical methods for assessing agreement between two methods of clinical measurement. Lancet 1986;1:307-10.

[15] Hallan SI, Coresh J, Astor BC, Asberg A, Powe NR, Romundstad S, Hallan HA, Lydersen S, Holmen J International comparison of the relationship of chronic kidney disease prevalence and ESRD risk. J Am Soc Nephrol 2006; 17:2275-84.

[16] Hallan S, Asberg A, Lindberg M, Johnsen H. Validation of the Modification of Diet in Renal Disease formula for estimating GFR with special emphasis on calibration of the serum creatinine assay. Am J Kidney Dis 2004;44:84-93.

[17] Selvin E, Manzi J, Stevens LA, Van Lente F, Lacher DA, Levey AS, Coresh J. Calibration of serum creatinine in the National Health and Nutrition Examination Surveys (NHANES) 1988-1994, 1999-2004. Am J Kidney Dis 2007;50:918-26.

[18] Macdonald J, Marcora S, Jibani M, Roberts G, Kumwenda M, Glover R, Barron J, Lemmey A. GFR estimation using cystatin $\mathrm{C}$ is not independent of body composition. Am $\mathbf{J}$ Kidney Dis 2006;48:712-19.

[19] Rule AD, Gussak HM, Pond GR, Bergstralh EJ, Stegall MD, Cosio FG, Larson TS. Measured and estimated GFR in healthy potential kidney donors. Am J Kidney Dis 2004;43:112-19.

[20] Van Den Noortgate NJ, Janssens WH, Delanghe JR, Afschrift MB, Lameire NH. Serum cystatin C concentration compared with other markers of glomerular filtration rate in the old old. J Am Geriatr Soc 2002;50:1278-82.

[21] Larsson A, Malm J, Grubb A, Hansson LO. Calculation of glomerular filtration rate expressed in $\mathrm{mL} / \mathrm{min}$ from plasma cystatin $\mathrm{C}$ values in $\mathrm{mg} / \mathrm{L}$. Scand J Clin Lab Invest 2004;64:25-30.

[22] Knight EL, Verhave JC, Spiegelman D, Hillege HL, de Zeeuw D, Curhan GC, de Jong PE. Factors influencing serum cystatin $\mathrm{C}$ levels other than renal function and the impact on renal function measurement. Kidney Int 2004;65:1416-21.

[23] Wang Y, Chen X, Song Y, Caballero B, Cheskin LJ. Association between obesity and kidney disease: a systematic review and meta-analysis. Kidney Int 2008;73:19-33.

[24] Bjarnadottir M, Grubb A, Olafsson I. Promoter-mediated, dexamethasone-induced increase in cystatin $\mathrm{C}$ production by HeLa cells. Scand J Clin Lab Invest 1995;55:617-23.

[25] Jayagopal V, Keevil BG, Atkin SL, Jennings PE, Kilpatrick ES. Paradoxical changes in cystatin $\mathrm{C}$ and serum creatinine in patients with hypo- and hyperthyroidism. Clin Chem 2003;49:680-1.

[26] Glassock RJ, Winearls C. An epidemic of chronic kidney disease: fact or fiction? Nephrol Dial Transplant 2008;23:1117-21. 